\title{
Evaluation of Free Radical Scavenging Activity of Various Leaf Extracts from Kedrostis foetidissima (Jacq.) Cogn.,
}

Vadivukkarasi Sasikumar ${ }^{\star}$ and Pavithra Kalaisezhiyen

Department of Biochemistry, KSR College of Arts and Science, Thokkavadi, Tiruchengode, Tamilnadu, India

*Corresponding author: Sasikumar V, Department of Biochemistry, KSR College of Arts and Science, Thokkavadi, Tiruchengode, Tamilnadu, India, Tel: 09865013448; E-mail: mailvadivusasi16@gmail.com

Rec date: Feb 28, 2014; Acc date: Apr 22, 2014; Pub date: May 5, 2014

Copyright: (C) 2014 Sasikumar V, et al. This is an open-access article distributed under the terms of the Creative Commons Attribution License, which permits unrestricted use, distribution, and reproduction in any medium, provided the original author and source are credited.

\begin{abstract}
The present study was to compare the effect of in vitro free radical scavenging activity between the various leaf extracts (aqueous, methanol, acetone chloroform and petroleum ether) of Kedrostis foetidissima. The free radical scavenging activity was found to be high in methanolic extract for DPPH, hydroxyl, nitric oxide, superoxide, hydrogen peroxide $\left(\mathrm{H}_{2} \mathrm{O}_{2}\right)$ radical in a concentration dependent manner followed by chloroform, aqueous, acetone and petroleum ether extracts. The metal chelating activity and reducing power ability was also similar as above. The content of total phenols, flavonoids and tannins was also found to be high in methanolic extract which may be correlated to its antioxidant activity. Thus the result suggests that the methanolic leaf extract of K.foetidissima could serve as a potential source of antioxidants and can be explored as a therapeutic agent in free radical induced diseases.
\end{abstract}

Keywords: Free radicals; Kedrostis foetidissima; Antioxidants; Phenols; Scavenging activity

\section{Introduction}

Free radicals are fundamental to any biochemical process and represent an essential part of aerobic life and metabolism [1]. Reactive Oxygen Species (ROS) and Reactive Nitrogen Species (RNS) are products of normal cellular metabolism [2]. The most common ROS include superoxide anion, $\mathrm{H}_{2} \mathrm{O} 2$, peroxyl $\left(\mathrm{ROO}^{-}\right)$radicals and reactive hydroxyl $\left(\mathrm{OH}^{-}\right)$radicals and the nitrogen derived free radicals are nitric oxide and peroxynitrite anion $\left(\mathrm{ONOO}^{-}\right)$[3]. These reactive species play an important role in pathogenesis of several oxidative stress related diseases like carcinogenesis, cardiovascular diseases, rheumatoid arthritis, ulcerative colitis and neurological degenerative diseases [4]. It is possible to reduce the risk of chronic diseases and prevent disease progression by either enhancing the body's natural antioxidant defenses or by supplementing with dietary antioxidants [5].

Antioxidants offer resistance against oxidative stress by scavenging the free radicals, inhibiting the lipid peroxidation and by many other mechanisms and thus prevent the disease progression [6]. The most commonly used synthetic antioxidants at present are Butylated Hydroxyanisole (BHA), Butylated Hydroxytoluene (BHT), Propyl Gallate and Tert-Butylhydroquinone. However, they are suspected of being responsible for liver damage and acting as carcinogens in laboratory animals [7]. The search for new products with antioxidative properties and fewer side effects is very active domain of research. Therefore, the development and utilization of more effective antioxidants of natural origin is desirable [8].

Since ancient times, many official herbs have provoked interest as sources of natural products. Novel natural antioxidants from some plants have been extensively studied in the past few years for their antioxidant and radical scavenging properties [9]. Kedrostis foetidissima (Jacq.) Cogn. Commonly known as "Appakovai" in Tamil is a medicinal plant found to be growing around the fence and have a very unpleasant smell but cattle feed on it ravenously. Kedrostis foetidissima belong to the family of Cucurbitaceae, traditionally the plant was found to be effective in treatment of diarrhea, measles, asthma, small pox and opportunistic infections. The present work was aimed to determine the phytochemical constituents and to compare the invitro free radical scavenging activity between the leaf extracts of K. foetidissima.

\section{Materials and Methods}

\section{Collection of plant materials}

The leaves of $K$. foetidissima were collected from Sivagiri, Tamilnadu, India during the month of January 2012 and authenticated by Dr. K. Nandakumar, Professor, Department of Botany, Kandaswami Kandars College, Velur, Namakkal (dt), Tamilnadu. The leaves were washed with distilled water, shade dried and powdered with the mechanical grinder. The powder was stored in an airtight container until further use.

\section{Chemicals}

Chemicals used in the study were ascorbic acid, gallic acid, tannic acid, catechol, butylated hydroxyl toluene, Folin-Ciocalteau reagent, 2, 2-diphenyl-1-picrylhydrazyl radical (DPPH), sodium carbonate, sodium nitrite, aluminium chloride, sodium hydroxide, potassium ferric cyanide, ferric chloride, sodium phosphate, ammonium molybdate, ferrous ammonium sulphate, Ethylenediaminetetraacetic Acid (EDTA), Dimethyl Sulphoxide (DMSO), ammonium acetate, $\mathrm{NADH}$, Nitro Blue Tetrasolium (NBT), Phenazine Methosulphate (PMS), hydrogen peroxide, sodium nitroprusside, sulphanilamide, Naphthyethylene Diamine Dihydrochloride (NEDD), glacial acetic acid, acetyl acetone, sulphuric acid, phosphoric acid, Trichloroacetic acid (TCA) and ferrozine. All the chemicals were purchased from , and all solvents used were of analytical grade. 


\section{Extraction of plant material}

The dried powder was extracted with solvents (aqueous, methanol, acetone, chloroform and petroleum ether). The sample powder $(10 \mathrm{~g})$ was extracted by stirring with $100 \mathrm{ml}$ of corresponding solvent at $25^{\circ} \mathrm{C}$ for $24 \mathrm{~h}$ and filtering through Whatman No.1 filter paper. The residue was then extracted with two additional $100 \mathrm{ml}$ portions of the solvent, as described above. The combined extracts were then rotary evaporated at $40^{\circ} \mathrm{C}$ to dryness. The combined extracts were kept in an oven at $40^{\circ} \mathrm{C}$ for removal of residual moisture.

The dried extracts were weighed to determine the percentage yield of the soluble constituents using the formula,

$\%$ Yield: (Weight of dry extract/ Weight taken for extraction) $\times 100$

\section{Determination of bioactive compounds in $K$. foetidissima}

Determination of total phenolic content: The total phenolic content in various leaf extracts of $\mathrm{K}$. foetidissima was assessed by Folin Ciocalteau's method [10]. To $1.0 \mathrm{ml}$ of the sample, $1.0 \mathrm{ml}$ of Folin Ciocalteau's reagent was added. After $3 \mathrm{~min}, 1.0 \mathrm{ml}$ of saturated $\mathrm{Na}_{2} \mathrm{CO}_{3}(\sim 35 \%)$ was added to the above mixture and the final volume was made up to $10 \mathrm{ml}$ with distilled water. The tubes were kept in dark for $90 \mathrm{~min}$, after which its absorbance were read at $725 \mathrm{~nm}$ against a reagent blank. Gallic acid was used as standard. Results were expressed as milligrams of Gallic Acid Equivalence (GAE) per gram of extract.

Determination of total flavonoid content: Total flavonoid content was determined by aluminium chloride method described by Kumar et al. [11] with minor modification. $0.5 \mathrm{ml}$ of the sample was mixed with $0.3 \mathrm{ml}$ of $5 \%$ sodium nitrite. After $5 \mathrm{~min} 0.3 \mathrm{ml}$ of $10 \%$ aluminium chloride was added. After $6 \mathrm{~min}, 2.0 \mathrm{ml}$ of $1 \mathrm{M}$ sodium hydroxide was added and the total volume was made up to $5.0 \mathrm{ml}$ with distilled water. The absorbance of the mixture was measured at 510 $\mathrm{nm}$ against a reagent blank. Catechol was used as standard. The flavonoid content was expressed as milligram of catechol equivalence (CAE) per gram of extract.

Determination of total tannin content: The quantitative tannin content in various leaf extracts was evaluated by the method reported by Price and Butler [12]. $0.5 \mathrm{ml}$ of the sample was mixed with $1.0 \mathrm{ml}$ of $1 \%$ potassium ferric cyanide and $1.0 \mathrm{ml}$ of $1 \%$ ferric chloride and the final volume was made to $10.0 \mathrm{ml}$ with distilled water. The reaction mixture was kept at room temperature for $5 \mathrm{~min}$, after which its absorbance were read at $720 \mathrm{~nm}$ against a reagent blank. The tannin content was expressed as milligram of tannic acid (TAE) equivalence per gram of extract.

Determination of Total antioxidant activity: The total antioxidant activity was evaluated by phosphomolybdenum method described by Prieto et al. [13]. $1.0 \mathrm{ml}$ of the extract was mixed with $1.0 \mathrm{ml}$ of the standard reagent solution $(0.6 \mathrm{M}$ sulphuric acid, $28 \mathrm{mM}$ sodium phosphate and $4 \mathrm{mM}$ ammonium molybdate). The tubes were capped and incubated in a thermal block at $95^{\circ} \mathrm{C}$ for $90 \mathrm{~min}$. After cooling to room temperature, the absorbance was measured at $695 \mathrm{~nm}$ against a reagent blank. The total antioxidant capacity was expressed as milligram of Ascorbic Acid Equivalence (AAE) per gram of extract.

\section{In Vitro free radical scavenging activity}

DPPH radical scavenging assay: DPPH radical scavenging assay is a widely used method to evaluate the free radical scavenging ability of natural compounds. This assay is based on the measurement of the scavenging ability of antioxidant substances towards the stable radical. The free radical scavenging activity of the extracts was examined in vitro using DPPH radical as described by Shimada et al. [14] with slight modification. $1.0 \mathrm{ml}$ of various concentrations of extracts (2-10 $\mathrm{mg} / \mathrm{ml}$ ) was mixed with $1.0 \mathrm{ml}$ of $0.8 \mathrm{mM}$ DPPH solution. The mixture was shaken vigorously and left to stand for $30 \mathrm{~min}$ and the absorbance was measured at $517 \mathrm{~nm}$ against a reagent blank. Gallic acid and BHT were used as standards. The inhibition percentage for scavenging DPPH radical was calculated according to the equation

$\%$ Decolorization $=\left[1-\left(\mathrm{ABS}_{\text {sample }} / \mathrm{ABS}_{\text {control }}\right] \times 100\right.$

Reducing power assay: The reducing power ability of the extracts was evaluated by the method described of Oyaizu [15]. The reaction mixture contained $1.0 \mathrm{ml}$ of various concentrations of extracts (2-10 $\mathrm{mg} / \mathrm{ml}), 2.5 \mathrm{ml}$ of $1 \%$ potassium ferricyanide and $2.5 \mathrm{ml}$ of $0.2 \mathrm{M}$ sodium phosphate buffer. The mixture was incubated at $50^{\circ} \mathrm{C}$ for 30 min and the reaction was terminated by the addition of $2.5 \mathrm{ml}$ of $10 \%$ TCA, followed by centrifugation at $3000 \mathrm{rpm}$ for $10 \mathrm{~min} .2 .5 \mathrm{ml}$ of the upper layer was mixed with $2.5 \mathrm{ml}$ of deionized water and $0.5 \mathrm{ml}$ of $0.1 \%$ ferric chloride. The absorbance was measured at $700 \mathrm{~nm}$ against blank. The reducing power ability of the sample is determined by increase in absorbance of the sample. BHT was used as standard for comparison.

Chelating ability on ferrous ions: The ferrous ion chelating potential of the extracts was evaluated by Dinis et al. [16] method. The reaction mixture contained $1.0 \mathrm{ml}$ of various concentrations of the extracts $(2-10 \mathrm{mg} / \mathrm{ml})$ and $0.05 \mathrm{ml}$ of $2 \mathrm{mM} \mathrm{FeCl}_{3}$. The reaction was initiated by the addition of $0.2 \mathrm{ml}$ of $5 \mathrm{mM}$ ferrozine. The reaction mixture was shaken vigorously and left standing at room temperature for $10 \mathrm{~min}$ and the absorbance of the reaction mixture was measured at $562 \mathrm{~nm}$ against a reagent blank. A lower absorbance of the reaction mixture indicated a higher ferrous ion chelating ability. The control contained all the reagents except sample. Gallic acid and ascorbic acid was used as standard for comparison.

\section{$\%$ Inhibition $=[($ Control- Test $) /$ control $] \times 100$}

Hydroxyl radical scavenging assay: Hydroxyl radical scavenging activity of the extracts was determined according to the method reported by Klein et al. [17]. The reaction mixture contained $1.0 \mathrm{ml}$ of different concentration of extracts $(2-10 \mathrm{mg} / \mathrm{ml}), 1.0 \mathrm{ml}$ of iron-EDTA solution $(0.13 \%$ ferrous ammonium sulphate $0.26 \%$ EDTA $), 0.5 \mathrm{ml}$ of $0.018 \%$ EDTA, $1.0 \mathrm{ml}$ of DMSO $(0.85 \%$ in $0.1 \mathrm{M}$ phosphate buffer pH7.4) and $0.5 \mathrm{ml}$ of $0.22 \%$ ascorbic acid. The tubes were capped tightly and heated in a water bath at $80-90^{\circ} \mathrm{C}$ for 15 minutes, the reaction was terminated by adding $1.0 \mathrm{ml}$ of ice-cold TCA $(17.5 \%)$. To the above reaction mixture $3.0 \mathrm{ml}$ of Nash reagent $(75.0 \mathrm{~g}$ of ammonium acetate, $3.0 \mathrm{ml}$ of glacial acetic acid and $2.0 \mathrm{ml}$ of acetyl acetone were mixed and distilled water was added to a total volume of $1 \mathrm{~L}$ ) was added and incubated at room temperature for 15 minutes for color development. The intensity of the yellow color formed was measured at $412 \mathrm{~nm}$ against a reagent blank. Ascorbic acid and gallic acid were used as standards.

\section{$\%$ inhibition $=[$ (Control- Test $) /$ control $] \times 100$}

Hydrogen peroxide scavenging assay: The ability of $K$. foetidissima plant extracts to scavenge hydrogen peroxide was estimated according to the method reported by Ruch et al. [18] with minor modification. A solution of hydrogen peroxide $(43 \mathrm{mM})$ is prepared in phosphate buffer (1 M pH 7.4). Different concentration of sample $(2-10 \mathrm{mg} / \mathrm{ml})$ was added to a hydrogen peroxide solution $(0.6 \mathrm{ml}, 43 \mathrm{mM})$. 
Absorbance of hydrogen peroxide at $230 \mathrm{~nm}$ was determined after 10 minutes against a blank solution containing phosphate buffer without hydrogen peroxide. Ascorbic acid was used as standard. The free radical scavenging activity was determined by evaluating $\%$ inhibition as above.

Nitric oxide radical scavenging assay: Nitric oxide generated from sodium nitroprusside interacts with oxygen to produce nitrite ions which was measured by the Griess reaction. This assay was done by the procedure described by Green et al. [19]. The reaction mixture contained $3.0 \mathrm{ml}$ of $10 \mathrm{mM}$ sodium nitroprusside in phosphate buffered saline $(\mathrm{pH} 7.4)$ and various concentration of $(2-10 \mathrm{mg} / \mathrm{ml})$ extracts. The resulting solution was then incubated at $25^{\circ} \mathrm{C}$ for 60 minutes. To the incubated sample $5.0 \mathrm{ml}$ of Griess reagent $(1 \%$ sulphanilamide, $0.1 \% \mathrm{NEDD}$ in $2 \% \mathrm{H} 3 \mathrm{PO} 4)$ was added and the absorbance of the chromophore formed was measured at $546 \mathrm{~nm}$ against a reagent blank. Percentage inhibition of the nitrite ions generated is observed. The standard ascorbic acid and BHT was used for comparison. The free radical scavenging activity was determined by evaluating $\%$ inhibition as above.

Superoxide anion radical scavenging assay: The superoxide anion radical scavenging activity of $K$. foetidissima leaf extracts were assessed using the method described by Fontana et al. [20] with slight modification. To various concentrations of the extracts $(2-10 \mathrm{mg} / \mathrm{ml})$, $1.0 \mathrm{ml}$ of phosphate buffer $(0.1 \mathrm{M}, \mathrm{pH} 7.2), 1.0 \mathrm{ml}$ of NADH $(2 \mathrm{mM})$, $1.0 \mathrm{ml}$ of NBT $(0.5 \mathrm{mM})$ and $0.1 \mathrm{ml}$ of PMS $(0.03 \mathrm{mM})$ were added. After 5 minutes incubation at room temperature, the absorbance was read at $562 \mathrm{~nm}$ against a reagent blank to determine the quantity of formazan generated. BHT and gallic acid was used as the standards. The $\%$ inhibition was determined as above.

Statistical analysis: Total phenol, flavonoids and tannin content and total antioxidant activity were compared using Student's t-test. The data were expressed as mean \pm S.E.M. Statistical differences at $\mathrm{p}<0.05$ between the data were analyzed by one way ANOVA followed by Duncan's Multiple Range Test (DMRT) using SPSS 15.0 software.

\section{Results and Discussion}

\section{\% Yield of sample}

The \% yield for Aqueous (AQKF), Methanol (MKF), Acetone (ACKF), Chloroform (CKF) and Petroleum Ether (PEKF) extracts of $K$. foetidissima were $10,6.66,4.3,6.0$ and 2.6 g respectively. The variation in the extraction yield depends on nature of the solvents and the chemical nature of the sample.

\section{Determination of bioactive compounds and total antioxidant activity in $K$. foetidissima}

Phytochemicals are non-nutritive plant chemicals that have protective or disease preventive properties. Medicinal plants are a source for a wide variety of natural products, such as the phenolic acids and flavonoids which are very interesting for their antioxidant properties [21]. Total phenols, flavonoids and tannin content in various leaf extracts of $K$. foetidissima were illustrated in Table 1. Among the five extracts, methanolic extract contained significant higher total phenol, flavonoid and tannin content $(224.83 \mathrm{mg}$ of GAE/g of extract, $176.18 \mathrm{mg}$ of CAE/g of extract, $101.91 \mathrm{mg}$ of TAE/g of extract respectively) followed by chloroform, aqueous, acetone and petroleum ether extracts. Plant phenolics exhibit an assay of solubility in solvents with different polarity and they constitute one of the major groups of compound acting as primary antioxidants and free radical terminators.

\begin{tabular}{|c|c|c|c|c|}
\hline \multirow{2}{*}{ Samples } & Phenols & Flavonoids & Tannins & \multirow{2}{*}{$\begin{array}{l}\text { Total antioxidant activity (mg } \\
\text { AAE/g of extract) }\end{array}$} \\
\hline & (mg GAE/g of extract) & (mg CAE/g of extract) & (mg GAE/g of extract) & \\
\hline AQKF & $152.5 \pm 2.5^{*}$ & $91.42 \pm 2.85^{*}$ & $57.66 \pm 1.01^{*}$ & $34.65 \pm 0.66^{*}$ \\
\hline MKF & $224.83 \pm 2.25^{*}$ & $176.18 \pm 5.9^{*}$ & $101.91 \pm 1.87^{*}$ & $60.88 \pm 1.0^{*}$ \\
\hline ACKF & $105.16 \pm 2.25^{*}$ & $60.94 \pm 4.36^{*}$ & $47.51 \pm 1.22^{*}$ & $31.32 \pm 0.66^{*}$ \\
\hline CKF & $177.5 \pm 2.5^{*}$ & $114.28 \pm 2.86^{*}$ & $88.91 \pm 1.0^{*}$ & $41.43 \pm 0.5^{*}$ \\
\hline PEKF & $57.5 \pm 2.5^{*}$ & $31.40 \pm 2.88^{*}$ & $23.75 \pm 1.25^{*}$ & $17.99 \pm 0.66^{*}$ \\
\hline
\end{tabular}

Table 1: Determination of bioactive compounds and total antioxidant activity in various leaf extracts of $K$. foetidissima

The total antioxidant activity of the extracts was measured spectrophotometrically through phosphomolybdenum method, which is based on the subsequent formation of $\mathrm{Mo}(\mathrm{IV})$ to $\mathrm{Mo}(\mathrm{V})$ with a maximum absorption at $695 \mathrm{~nm}$. The higher the absorbance, stronger is the antioxidant activity. The total antioxidant activity was found to be higher in methanolic extract ( $60.88 \mathrm{mg}$ of AAE/g of extract). The total antioxidant activity of the five extracts, was found to decrease in the order MKF $>$ CKF $>$ AQKF $>$ ACKF $>$ PEKF (Table 1).

The Phenolic compounds are a large group of phytochemicals which have received considerable attention for being potentially protective factors against cancer and heart diseases, because of their potent antioxidative properties. Phenolic compounds and flavonoids have been reported to be associated with antioxidative action in biological systems, acting as scavengers of singlet oxygen and free radicals [22]. The total phenolic content was found high in methanolic extract when compared to other extracts, which corresponds to its various radical scavenging activities. Several reports have shown close relationship between total phenolic content and antioxidative activity of the fruits, vegetables and plants [23].

\section{In vitro free radical scavenging activity}

Several in vitro model systems have been used for assessing the scavenging activity in various leaf extracts of $K$. foetidissima. 
DPPH is a stable nitrogen-centered free radical commonly used for testing radical scavenging activity of the compound or plant extracts. When the stable DPPH radical accepts an electron from the antioxidant compound, the violet color of the DPPH radical was reduced to yellow colored Diphenylpicrylhydrazine radical which was measured colorimetrically. Substances which are able to perform this reaction can be considered as antioxidants and therefore radical scavengers [24]. DPPH radical scavenging activity of various leaf extracts of $K$. foetidissima was denoted in Figure 1 . All the extracts showed different levels of DPPH radical scavenging activity over the range of $2-10 \mathrm{mg} / \mathrm{ml}$ concentration and the EC50 value of AQKF, MKF, ACKF, CKF and PEKF was found to be 4.8, 1.2, 7.0, 1.8 and 7.6 $\mathrm{mg} / \mathrm{ml}$ respectively. MKF exhibited strongest $\mathrm{DPPH}$ radical scavenging activity compared to other extracts. The extracts radical scavenging activity were effective in the order MKF $>$ CKF $>$ AQKF $>$ ACKF > PEKF. BHT and gallic acid were used as standards at the concentration $20-100 \mu \mathrm{g} / \mathrm{ml}$ and the EC50 value was found to be 60 and $46 \mu \mathrm{g} / \mathrm{ml}$ respectively. Standards and all the extracts showed a dose dependent inhibition on the DPPH radicals.

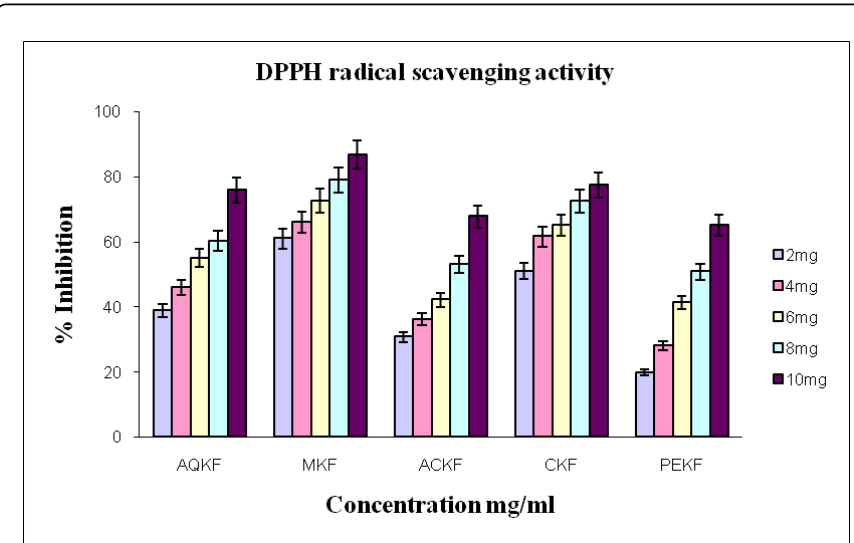

Figure 1: DPPH radical scavenging activity of various leaf extracts of $K$. foetidissima

Fe (III) reduction is often used as an indicator of electron donating activity, which is an important mechanism of phenolic antioxidant action [25]. The reducing ability of a compound generally depends on the presence of reductones (antioxidants), which exert the antioxidant activity by breaking the free radical chain by donating a hydrogen atom [26]. Figure 2 depicts the reductive capabilities of various extracts of $K$. foetidissima. Like antioxidant activity, reducing power of the extracts increases with the increase in concentration. When compared to other extracts MKF exhibited highest reducing power ability. Reducing power ability of the five extracts was found to decrease in the order MKF > CKF > AQKF > ACKF > PEKF. The extracts showed good reducing power ability in a dose dependent manner which was comparable to that of standards. The antioxidant principles present in the extracts of $K$. foetidissima caused the reduction of $\mathrm{Fe} 3+/$ ferricyanide complex to the ferrous form and thus proved the reducing power ability. The reducing power ability was compared with standard BHT at a concentration of $20-100 \mu \mathrm{g}$ at 0.3-0.85 OD respectively.

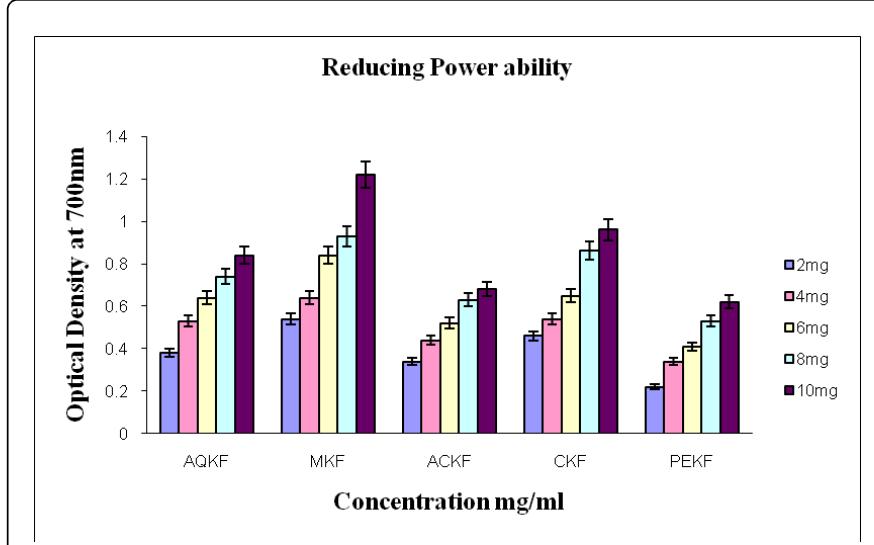

Figure 2: Reducing power ability of various leaf extracts of $K$. foetidissima

Iron is essential for life as it is required for oxygen transport, respiration and for activity of many enzymes. Chelating agents inhibit lipid peroxidation by stabilizing the transition metals [27]. Decrease in the red color ferrozine-Fe2+ complex indicates high radical scavenging activity of the compound. Earlier in, Gordon [28] reported that the chelating agents are effective as secondary antioxidants because they reduce the redox potential, thereby stabilizing the oxidized form of the metal ion. The metal chelating ability of various leaf extracts of $K$. foetidissima was represented in Figure 3. The MKF exhibited strongest ferrous ion chelating ability compared to other extracts. The EC50 values of AQKF, MKF, ACKF, CKF and PEKF were 2.4, 1.0, 5.0, 1.8 and $7.6 \mathrm{mg} / \mathrm{ml}$ respectively. The extracts chelating ability were found to be effective in the order MKF $>$ CKF $>$ AQKF $>$ ACKF $>$ PEKF. The scavenging activity of the all extracts was comparable to ascorbic acid and BHT at the lowest concentration $0.1 \mathrm{mg} / \mathrm{ml}$. The chelating effect of the extracts increases with the increase in the concentration this may be due to the increase in the concentration of the secondary metabolites in the extracts. The EC50 values of ascorbic acid and BHT were found to be 42 and $56 \mu \mathrm{g}$ respectively.

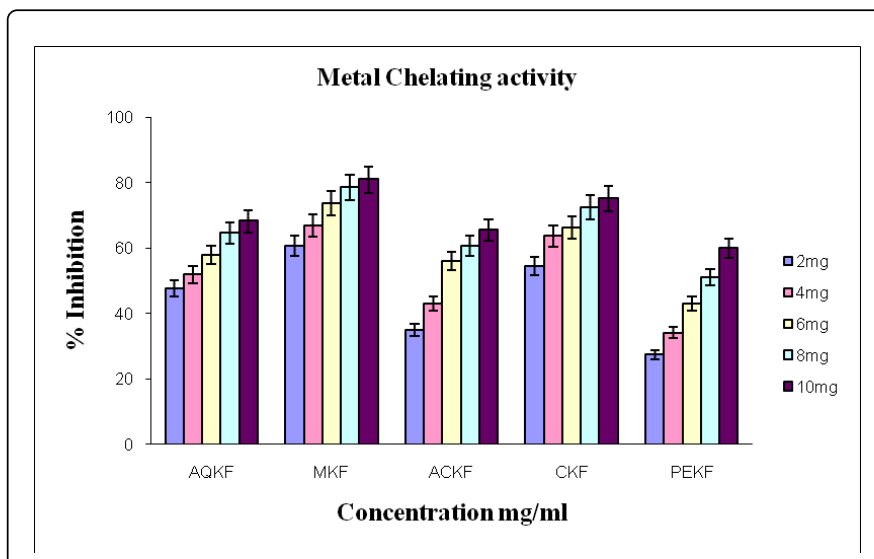

Figure 3: Metal Chelating activity of various leaf extracts of $K$. foetidissima

Hydroxyl radical is the most reactive oxygen centered species and causes severe damage to adjacent biomolecule. Hydroxyl radical scavenging activity was estimated by generating the hydroxyl radicals 
using ascorbic acid-iron EDTA. The hydroxyl radicals were formed by the oxidation reaction with the Dimethyl Sulphoxide (DMSO) to yield formaldehyde, which provides a convenient method to detect hydroxyl radicals by treatment with Nash reagent. Figure 4 represents the hydroxyl radical scavenging activity of various leaf extracts of $K$. foetidissima. The MKF exhibited highest hydroxyl radical scavenging activity compared to other extracts. The EC50 values of AQKF, MKF, ACKF, CKF and PEKF, were 6.0, 2.0, 7.0, 2.8, $7.6 \mathrm{mg} / \mathrm{ml}$ respectively. The decreasing order of hydroxyl radical scavenging activity of the extracts was found to be MKF $>$ CKF $>$ AQKF $>$ ACKF $>$ PEKF. All the extracts of $K$. foetidissima when added to the reaction mixture scavenge hydroxyl radicals in a concentration dependent manner. The scavenging of the hydroxyl radicals may be due to the presence of phenolic compounds in the extracts. The EC50 values of gallic acid and ascorbic acid were found to be 40 and $56 \mu \mathrm{g}$ respectively.

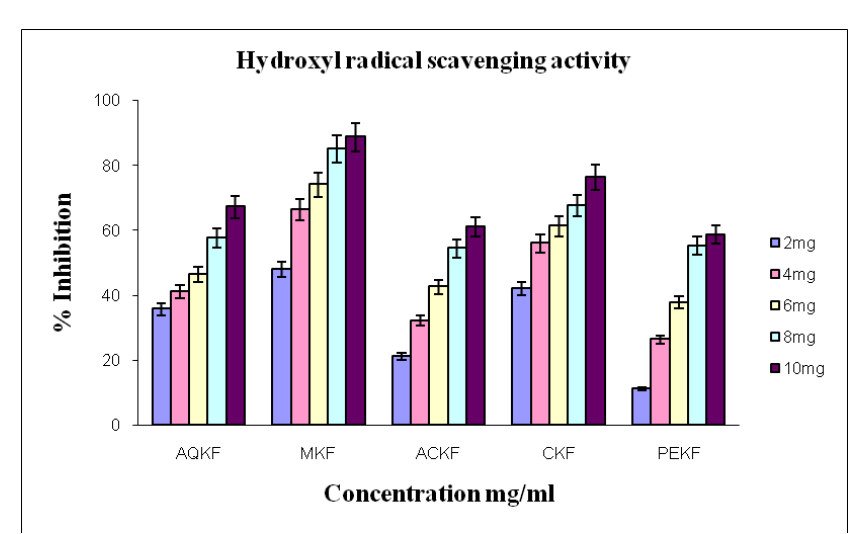

Figure 4: Hydroxy radical scavenging activity of various leaf extracts of $K$. foetidissima

$\mathrm{H}_{2} \mathrm{O}_{2}$ is highly important because of its ability to penetrate into biological membranes. $\mathrm{H}_{2} \mathrm{O}_{2}$ itself is not very reactive, but it can sometimes be toxic to cell because it may give rise to hydroxyl radicals in the cells [29]. Scavenging of $\mathrm{H}_{2} \mathrm{O}_{2}$ by extracts may be attributed to their phenolics, which can donate electrons to $\mathrm{H}_{2} \mathrm{O}_{2}$, thus neutralizing it to water [30]. The results show the all the extracts had potent $\mathrm{H}_{2} \mathrm{O}_{2}$ scavenging activity which may be due to the antioxidant compounds. As the antioxidant components present in the extracts are good electron donors, they may accelerate the conversion of $\mathrm{H}_{2} \mathrm{O}_{2}$ to $\mathrm{H}_{2} \mathrm{O}$. Figure 4 reports the $\mathrm{H}_{2} \mathrm{O}_{2}$ scavenging activity of various leaf extracts of $K$. foetidissima. The MKF was shown to scavenge the $\mathrm{H}_{2} \mathrm{O}_{2}$ radicals with an excellent inhibition percentage of $30-80 \%$. The EC50 values of AQKF, MKF, ACKF, CKF and PEKF were 8.0, 3.8, 7.0, 5.0, $8.8 \mathrm{mg} / \mathrm{ml}$. All the leaf extracts of $K$. foetidissima exerted moderate scavenging activity when compared to ascorbic acid with EC50 value of $46 \mu \mathrm{g}$. The scavenging activity of the extracts were effective in the order MKF > $\mathrm{CKF}>\mathrm{ACKF}>\mathrm{AQKF}>\mathrm{PEKF}$.

Nitric oxide is a potent pleiotropic mediator of various physiological processes. It is a diffusible free radical, which plays many roles as an effectors molecule in diverse biological systems [31]. Nitric oxide radical scavenging activity of various extracts of $K$. foetidissima was presented in Figure 5. All the extracts of $K$. foetidissima effectively reduced the generation of nitric oxide from sodium nitroprusside. MKF showed highest nitric oxide radical inhibition compared to other extracts. The EC50 value of AQKF, MKF, ACKF, CKF, and PEKF were $5.2,1.6,5.6,2.0$ and $6.2 \mathrm{mg} / \mathrm{ml}$ respectively. The extracts radical scavenging activity was found to be MKF > CKF > AQKF > ACKF> PEKF. The degree of inhibition of the NO free radicals was found to be increased in increasing concentration of the $K$. foetidissima leaf extracts, this indicates that the extract may contain compounds capable of inhibiting the generation of nitric oxide and offers scientific evidence for the use of $K$. foetidissima leaves in the treatment of various diseases. The EC50 values of BHT and ascorbic acid were found to be 42 and $40 \mu \mathrm{g}$ respectively.

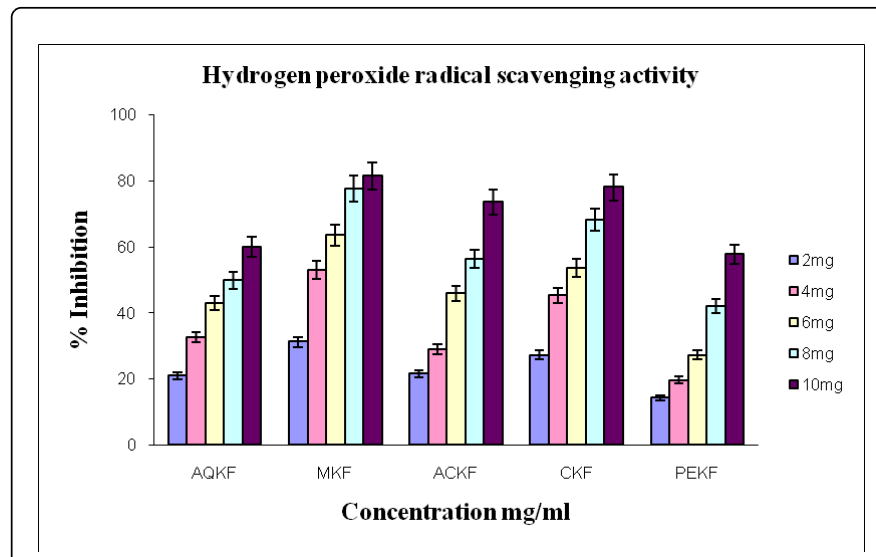

Figure 5: Hydrogen peroxide radical scavenging activity of various leaf extracts of $K$.foetidissima

Superoxide anion is a weak oxidant produced during various biological reactions is highly toxic [32]. In the PMS/NADH-NBT system, the superoxide anion derived from dissolved oxygen from PMS/NADH coupling reaction reduces NBT [33]. Superoxide anion radical is known as an initial radical and plays an important role in the formation of other reactive oxygen-species, such as hydrogen peroxide or singlet oxygen. Superoxide is generated in vivo by several oxidative enzymes, including xanthine oxidase. A decrease in absorbance indicated the antioxidant activity of the extracts which may be due to the inactivation or consumption of superoxide anion radicals produced in the reaction mixture. Superoxide anion radical scavenging activity of various extracts of $K$. foetidissima was denoted in Figure 6. The decrease of absorbance indicates the consumption of superoxide anion in the reaction mixture. The MKF showed highest superoxide radical scavenging activity among the five extracts and the EC50 value of AQKF, MKF, ACKF, CKF and PEKF were 7.4, 3.2, 8.6, 4.2, 9.6 $\mathrm{mg} / \mathrm{ml}$. The EC50 values of BHT and gallic acid were found to be 70 and $40 \mu \mathrm{g} / \mathrm{ml}$ respectively. The scavenging of superoxide anion radicals of the extracts were found to be effective in the order MKF > $\mathrm{CKF}>\mathrm{AQKF}>\mathrm{ACKF}>\mathrm{PEKF}$. 


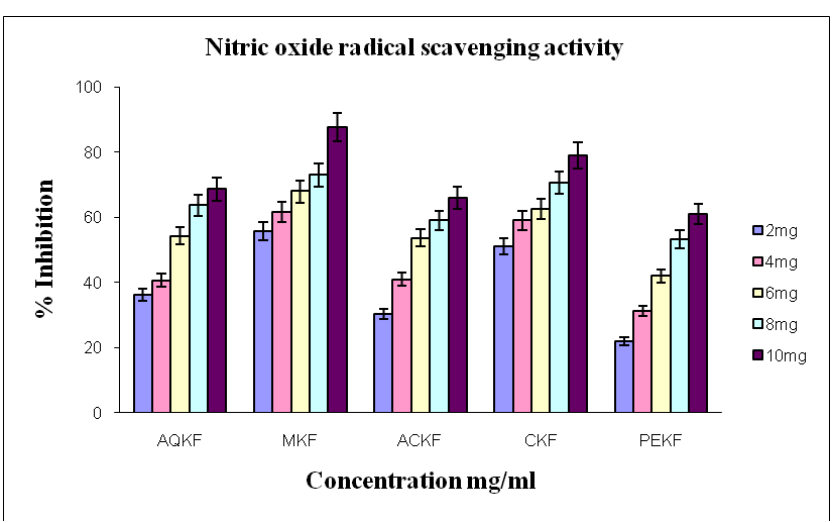

Figure 6: Nitric oxide radical scavenging activity of various leaf extracts of $K$. foetidissima

\section{Conclusion}

Today, antioxidative properties of the plants have become a great interest due to their possible uses as natural additives to replace synthetic ones. The results of the present study showed that all the extracts exhibited potent antioxidant activity. Among the five extracts methanolic extract exhibited higher potency of free radical scavenging activity. The scavenging activity of $K$. foetidissima leaf extracts shows similar trend with the result of total phenolic content, indicating that the free radical scavenging activity of $K$. foetidissima leaf extracts is highly related to the presence of hydroxyl groups in the phenolic compounds. Thus present data suggest that methanolic extract can be used as a good source of natural antioxidants for health benefits and further isolation of bioactive compounds are required for identifying the unknown compounds to establish their pharmacological properties.

\section{Acknowledgment}

The authors thank the Management of KSR College of Arts and Science, Tiruchengode, India and Dr. N. Kannan, Principal of this college for their encouragement.

\section{References}

1. Tiwari A (2001) Imbalance in antioxidant defense and human diseases: Multiple approach of natural antioxidants therapy. Curr Sci 81: 1179-1187.

2. Sudha G, Sangeetha priya M, Indhu shree R, Vadivukkarasi S (2011) In vitro free radical scavenging activity of raw pepino fruit (solanum muricatum aiton). Int J Curr Pharm Res: 137-140.

3. Joyce DA (1987) Oxygen radicals in disease. Adv Drug Reac Bull 127: 476-479.

4. Halliwell B, Gutteridge JM (1990) Role of free radicals and catalytic metal ions in human disease: an overview. Methods Enzymol 186: 1-85.

5. Stanner SA, Hugher J, Kelly CN, Butlriss JA (2000) Review of the epidemiological evidence for the antioxidant hypothesis. Public health Nutrition 7: 401-422.

6. Braughler JM, Duncan LA, Chase RL (1986) The involvement of iron in lipid peroxidation. Importance of ferric to ferrous ratios in initiation. J Biol Chem 261: 10282-10289.
7. Anagnostopoulou MA, Kefalas P, Papageorgiou VP, Boskou D (2006) Radical scavenging activity of various extracts and fractions of sweet orange peel (Citrus sinensis). Food Chem 94: 19-25.

8. Sakagami H1, Aoki T, Simpson A, Tanuma S (1991) Induction of immunopotentiation activity by a protein-bound polysaccharide, PSK (review). Anticancer Res 11: 993-999.

9. Sangameswaran B, Chubhale Deshraj, Balakrishnan BR, Jayakar B (2008) Hepatoprotective effects of Thespesia lampas. Dhaka Uni J Pharm Sci 7: 11- 13.

10. Singleton VL, Rossi JA (1965) Colorimetry of total phenolics with phosphomolybdic-phosphotungstic acid reagents. American Journal of Enology and Viticulture 16: 144-158.

11. Kumar S, Kumar D, Manjusha, Kamal Saroha, Nidhan Singh et al. (2008) Antioxidant free radical scavenging potential of Citrullus colocynthis (L) Schrad Methanolic fruit extract. Acta pharma 58: 215-220.

12. Price ML. Butler LG (1977) Rapid visual estimation and spectrophotometric determination of tannin content of sorghum grain. J Agric Food Chem 25: 1268-1273.

13. Prieto P, Pineda M, Aguilar M (1999) Spectrophotometric quantitation of antioxidant capacity through the formation of a phosphomolybdenum complex: specific application to the determination of vitamin E. Anal Biochem 269: 337-341.

14. Shimada K, Fujikawa K, Yahara K, Nakamura T (1992) Antioxidative properties of xanthan on the autioxidation of soybean oil in cyclodextrin emulsion. J Agric Food Chem 40: 945- 948.

15. Oyaizu M (1986) Studies on products of browning reaction: Antioxidative activities of products of browning reaction prepared from glucosamine. Jpn J Nutr 44: 307-315.

16. Dinis TCP, Madeira VMC, Almeida LM (1994) Action of phenolic derivatives (acetaminophen, salicylate, and 5-aminosalicylate) as inhibitors of membrane lipid peroxidation and as peroxyl radical scavengers. Arch Biochem Biophys 315: 161 - 169.

17. Klein SM, Cohen G, Cederbaum AI (1981) Production of formaldehyde during metabolism of dimethyl sulfoxide by hydroxyl radical generating systems. Biochemistry 20: 6006-6012.

18. Ruch RJ1, Cheng SJ, Klaunig JE (1989) Prevention of cytotoxicity and inhibition of intercellular communication by antioxidant catechins isolated from Chinese green tea. Carcinogenesis 10: 1003-1008.

19. Green LC, Wagner DA, Glogowski J, Skipper PL, Wishnok JS, et al. (1982) Analysis of nitrate, nitrite, and [15N]nitrate in biological fluids. Anal Biochem 126: 131-138.

20. Fontana L, Giagulli C, Minuz P, Lechi A, Laudanna C (2001) 8-Iso-PGF2 alpha induces beta 2 -integrin-mediated rapid adhesion of human polymorphonuclear neutrophils: a link between oxidative stress and ischemia/reperfusion injury. Arterioschler Thromb Vasc Biol 21: 55 -60.

21. Wong C, Li H, Cheng K, Chen F (2006) A systematic survey of antioxidant activity of 30 Chinese medicinal plants using the ferric reducing antioxidant power assay. Food Chem 97: 705-711.

22. Jørgensen LV, Madsen HL, Thomsen MK, Dragsted LO, Skibsted LH (1999) Regeneration of phenolic antioxidants from phenoxyl radicals: an ESR and electrochemical study of antioxidant hierarchy. Free Radic Res 30: $207-220$.

23. Abdille MH, Singh RP, Jayapraksha GK, Jena BS (2005) Antioxidant activity of the extracts from Dillenia indica fruits. Food Chem 90 : 891-896.

24. Dehpour AA, Ebrahimzadeh MA, Nabavi SF, Nabavi SM (2009) Antioxidant activity of methanol extract of Ferula assafoetida and its essential oil composition. Grasas Aceites 60: 405-412.

25. Nabavi SM, Ebrahimzadeh MA, Nabavi SF, Fazelian M, Eslami B (2009a) In vitro antioxidant and free radical scavenging activity of Diospyros lotus and Pyrus boissieriana growing in Iran. Pharmacognosy Magazine 4: 123-127.

26. Meir S, Kanner J, Akiri B, Hadar SP (1995) Determination and involvement of aqueous reducing compounds in oxidative systems of various senescing leaves. J Agric Food Chem 43: 1813-1817. 
Citation: Sasikumar V, Kalaisezhiyen P (2014) Evaluation of Free Radical Scavenging Activity of Various Leaf Extracts from Kedrostis foetidissima (Jacq.) Cogn.,. Biochem Anal Biochem 3: 150. doi:10.4172/2161-1009.1000150

Page 7 of 7

27. St Angelo AJ (1992) Lipids oxidation in food, ACS Symposium Series, American Chemical Society Washington DC: 500.

28. Gordon MH (1990) The mechanism of antioxidant action in vitro, In: Hudson BJF (editor), Food antioxidants. Elsevier Applied Science London 1-18.

29. Gulcin I, Huyut Z, Elmastas M, Aboul-Enein HY (2010) Radical scavenging and antioxidant activity of tannic acid. Arab J Chem 43-53.

30. Ebrahimzadeh MA, Nabavi SF, Nabavi SM (2009) Antioxidant activities of methanol extract of Sambucus ebulus L. flower. Pak J Biol Sci 12: 447-450.
31. Miller MJ, Sadowska-Krowicka H, Chotinaruemol S, Kakkis JL, Clark DA (1993) Amelioration of chronic ileitis by nitric oxide synthase inhibition. J Pharmacol Exp Ther 264: 11-16.

32. Stief TW (2003) The physiology and pharmacology of singlet oxygen. Med Hypotheses 60: 567-572.

33. Toda S, Ohnishi M, Kimura M, Nakashima I (1988) Action of curcuminoids on the hemolysis and lipid peroxidation of mouse erythrocytes induced by hydrogen peroxide. J Ethnopharmacol 23: 105-106. 